\title{
Prof Luc Picard-Tribute to a Legend in Interventional Neuroradiology
}

\author{
Rajanikanth R. Vedula ${ }^{1,2}$ \\ ${ }^{1}$ Clinical Director of Interventional Radiology \& Program Director \\ of DNB, National Board Examinations, Krishna Institute of Medical \\ Sciences, Secunderabad, Telangana, India \\ 2 Professor and Head of Department Radiology \& Imaging, Sree \\ Chitra Tirunal Institute for Medical Sciences and Technology, \\ Thiruvananthapuram, Kerala, India
}

J Clin Interv Radiol ISVIR 2021;5:131-132.

Prof. Luc Picard, the pioneer French interventional neuroradiologist passed away in April 2021. Absence of his towering figure is a profound loss to neuroradiology, in particular, to the discipline of interventional neuroradiology. Luc Picard was born in Metz, Germany, on November 29, 1937. His father was a family doctor. He was the last of the four children (one brother and two sisters). He was educated in Nancy in Saint Sigisbert College (Catholic college) and then in the Faculty of medicine in Nancy. He is survived by his wife Françoise, a neuropsychiatrist and a brilliant analyst, three children (two daughters and a son who is a family physician near Nancy), nine grandchildren and a great grandchild.

He started his training as a clinical neurologist in the early 1960s. Realizing the importance of radiology in neurological diagnosis, he completed additional specialization with a diploma in neuroradiology. He was closely associated with Dr. Rene Djindjan, a pioneer and authority on spinal vasculature and angiography before joining the Department of Radiology in Nancy, France, in 1970. Soon after, he set up an independent division of neuroradiology, thereafter upgraded it to a full-fledged department in 1977, and served as its Director (1977-1980), Professor (1980-1984), and Chairman (19842004). He spent his entire career working at this institution until his retirement. In his long career spanning five decades, Prof. Picard held many notable positions-the Professor of Neuroradiology, President of the World Federation of Neuroradiological Societies, and Honorary President of the World Federation of Interventional and Therapeutic Neuroradiology. He was also a founder member of the French Society of Neuroradiology in 1970 and became its President in 1989. He was the Editor of the Journal of Neuroradiology from 1978 to 2002. A detailed biographical sketch of this pioneer is available in the following links (htpp://www.sfrnet. org).$^{1,2}$

DOI https://doi.org/ $10.1055 / \mathrm{s}-0041-1730759$ ISSN 2457-0214
Address for correspondence Rajanikanth R. Vedula, MD, DMRD, FRCP (Glasgow), Apartment no. 101 Woods, Somajiguda Rajbhavan Road, Hyderabad 500082, Telangana, India (e-mail: vedula@gmail.com).

My first interaction with Prof. Picard was in 1986when he visited Sree Chitra Tirunal Institute for Medical Sciences and Technology (SCTIMST), Thiruvananthapuram ( Picard delivered guest lectures and demonstrated the techniques of superselective embolization, balloon occlusion, and other techniques that had just become current in the practice of neurointervention in the 1980s. His visit was the impetus and catalyst for transforming our fledgling Interventional Neuroradiology program at SCTIMST into a full-fledged state-of-the-art clinical service. Prof. Picard taught me and my colleagues the use of Ingenor microcatheters, the injection chamber for propelling the catheters under hydrostastic pressure into the cerebral circulation, creating a calibrated leak in the microballoons and mounting them in the microcatheters using latex ligatures. He also demonstrated the correct technique of preparing isobutyl cyanoacrylate (2-IBCA), the then available liquid polymerizing embolic agent, with Myodil and tantalum powder. He performed superselective angiography in a patient with cerebral arterovenous malformation (AVM), deftly navigating the microcatheter into the feeding branch of the middle cerebral artery. Having almost approached the nidus using the Balt Pursil microcatheter in another AVM, he abandoned the procedure, a great lesson to us when and why not to deliver 2-IBCA in the given circumstance. He treated two other patients, one with a peripheral vascular malformation in the leg and the other with an aneurysm of the internal carotid artery near the skull base. He would often quote his first-time experience of witnessing seizures following intra-arterial injection of papaverine in a young female patient for the relief of vasospasm, while demonstrating the procedure at our Institute. His lectures illustrated with excellent, glass-mounted $35-\mathrm{mm}$ slides on a range of topics from treatment of cerebral AVMs, aneurysms, carotid-cavernous fistulae, and spinal AVMs revealed the

(c) 2021. Indian Society of Vascular and Interventional Radiology. This is an open access article published by Thieme under the terms of the Creative Commons Attribution-NonDerivative-NonCommercial-License, permitting copying and reproduction so long as the original work is given appropriate credit. Contents may not be used for commercial purposes, or adapted, remixed, transformed or built upon. (https://creativecommons.org/licenses/by-nc-nd/4.0/).

Thieme Medical and Scientific Publishers Pvt. Ltd. A-12, 2nd Floor, Sector 2, Noida-201301 UP, India 


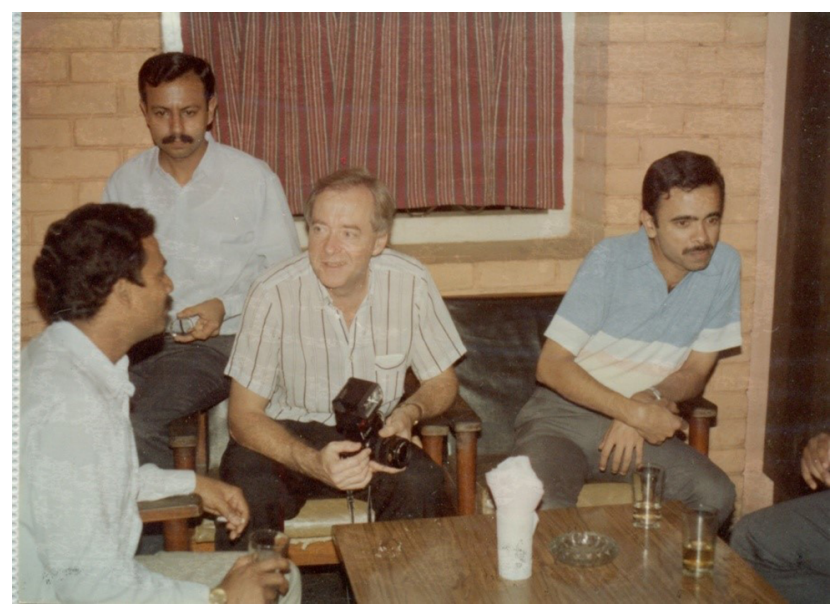

Fig. 1 Prof. Luc Picard (holding the camera) discussing with colleagues at Sree Chitra Tirunal Institute for Medical Sciences and Technology (SCTIMST).

phenomenal amount of work that this pioneer had undertaken to advance the field of neurointerventional radiology. Current concept of transvenous approach to cerebral AVMs may be based on his simple anatomical drawings of flow dynamics. With profound gratitude, I presented him with ready to use sterilized packets of hydrogel microspheres synthesized at our Research and Development Wing, an embolic material he was unfamiliar with. It was indeed our great fortune to have been guided and tutored by Prof. Picard. Despite restrictions on short-term visits he took personal interest and facilitated my trip to his center at Nancy, France, in the late 1990s. I saw him meticulously noting down relevant and critical points before the procedure in every case file. Organization of his workflow, follow-up, and documentation were extraordinary to emulate.

Off working hours Dr. Picard was a very friendly person with a subtle and wry sense of humor (-Fig. 2). He spoke English with a charming continental accent that was special

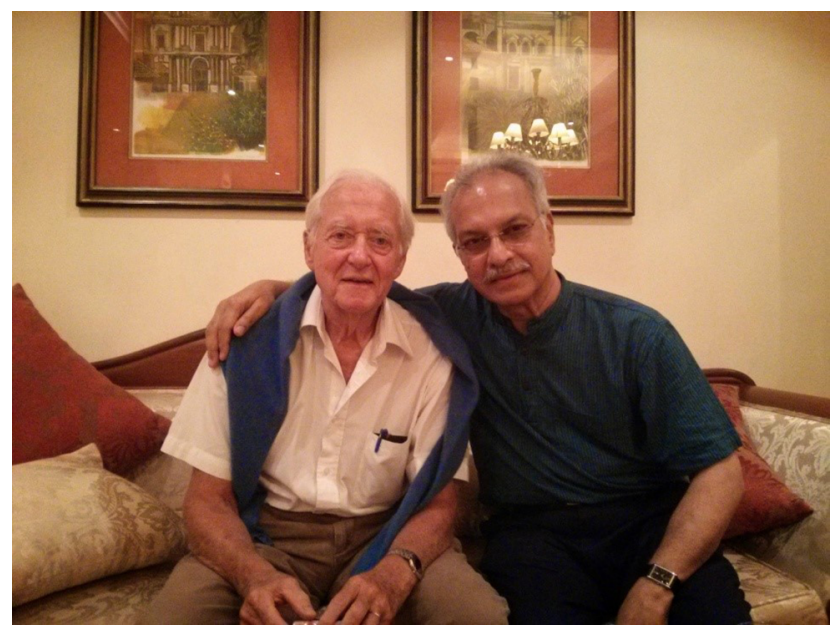

Fig. 2 Prof. Luc Picard (wearing white shirt) with the author Rajanikanth R. Vedula.

and amusing. He enjoyed Indian food and regaled us with stories of his visits to other parts of the world, including Shanghai (China had not yet opened up then). He was a fan of modern theatre and art with interest in geopolitics.

The demise of Prof. Luc Picard is a great loss to the fraternity of radiologists, particularly the neuroradiologists. He will be missed and will never be forgotten by the interventional community of India. May his soul rest in peace.

\section{Conflict of Interest}

None declared.

\section{References}

1 Laudatio ML, Lectio Magistralis LP, Laurea Honoris Causa in Honour of Prof Luc Picard. Interv Neuroradiol 2010;16:121-126

2 AuntMinnieEurope. SFR pays tribute to neuroradiologist Prof. Luc Picard. Available at: https://www.auntminnieeurope. com/index.aspx?sec=ser\&sub=def\&pag=dis\&ItemID=620059. Accessed May 6, 2021 